\title{
Delta Building: Science, Engineering, and an Opportunity for Design Leadership
}

\author{
JEFFREY A. CARNEY \\ Louisiana State University
}

Trans-disciplinary design research is leading to significant academic production, pedagogical innovation, and in the process transforming architectural design practice. Melding parallel movements of "design thinking" and "trans-disciplinary Research", architecture is centrally positioned to achieve significant agency in the increasingly urgent effort to adapt to climate change. In the university setting, this has enabled new institutes to develop rapidly, creating new opportunities and challenges for architectural education, research, and practice.

\section{INTRODUCTION}

Climate change threatens far more than the structural integrity of the built environment. At the height of the period of anthropogenic control of the world around us, climate change forces us to consider the indeterminate and dynamic aspects of the environment and its effects on human civilization. The decision-making process, policy framework, urban form, funding mechanisms and many other issues will be challenged by this new paradigm. Framing the university response to research related to climate change has been the development of trans-disciplinary research centers. Located in various departments these centers are increasingly significant spaces for research production, pedagogical innovation, and community engagement in a rapidly changing environment. The spatial design fields of architecture, landscape architecture, and city planning are well positioned and suited to achieve significant agency in this new research landscape. The increasingly urgent effort to adapt to climate change positions design thinking as an actionable structure to activate broad-based trans-disciplinary teams. Design bridges the often tremendous gaps between academic disciplines through a focus on applications, communication, and community engagement. The iterative project focus of design education and research is the perfect platform for making change that links the university with the broader community.

Within the university the deep silos of discipline-specific research are being fundamentally challenged by the growing search for integrated solutions and applications to problems at the interface of science, infrastructure, and society. An emergent focus around the issues of climate change as a synthetic, systems based, and socially motivated challenge can focus university research output around issues immediately important to society while simultaneously feeding deep research questions. For design education, research, and service the establishment and leadership of large, significantly-funded centers of research is well within reach. Social pressures on universities for tangible products, federal funding agencies pressing for action, and an increasing entrepreneurial bridge between design and urban development is leading to a far more innovative environment for higher education and university research.

Design links science and society, theory and practice. As it is both the product and activity, design provides both process and result. The broad meaning of the word - both active and object - is a perfect method for the iterative process of innovating in times of great uncertainty and change. (Nassauer 2008) The goal of this paper is to lay out an argument for significant engagement of university-based design research in larger research efforts toward resilience and sustainability in reaction to climate change. Design education holds a special place in the university. Located between the humanities, arts, and sciences, our process is in many ways central to all at the same time peripheral to each. The adaptation of human settlement will require data modeling, scientific research, and advanced engineering, but these tools must be applied to problems through the integrative lens of design. Far from a choice between design and science, or design and service, the opportunities that this moment holds are for an expansion of design as a core principle of decision making and policy, expanding the voice of designers on campus and beyond.

\section{A NEW CLIMATE FOR DESIGN RESEARCH}

Over the past decade, society has experienced the results of increased risk from storm and flood. From Hurricane Katrina a decade ago, to Hurricane Sandy in 2012, we are entering a time marked by increasing environmental disturbance exacerbated by global climate change. During this decade, the concept of resilience has entered the mainstream and captured significant attention in policy, research, practice, and academia. Resilience acknowledges a delicate balance between the dynamic ecological system and the stable structure upon which society is largely built. However, in a time where disturbances will at times overwhelm our ability to rebound and sustain the 
status quo, we will need to adapt and transform alongside the disturbance. The concept of resilience is able to account for the return to stability as well as this potential "bounce forward" or adaptation. As the term itself is continually debated and redefined it in fact, can mean both. Resilience has been defined in terms of engineering - the ability of an object in stress to return to normal. The fundamental consideration in this paradigm is making objects or systems strong enough to survive a stress and find their way back to equilibrium. The ecological definition of resilience differs in a fundamental way. Davoudi describes resilience as, "not conceived of as a return to normality, but rather as the ability of complex socio-ecological systems to change, adapt, and crucially, transform in response to stresses and strains." (Davoudi 2012) The focus of ecological resilience is not the eventual return to a stable state but the transformative potential of the disturbance itself. The disturbance introduces energy into a complex system that has the potential to transform the system. In terms of social ecological systems, resilience becomes the ability to harness the power of the disturbance, not merely the ability to defend against such a risk. Thus resilience, far from a defensive position, requires a nimble and creative acuity to imagine and act to create what could be from what currently is.

Climate change is also challenging many long held research paradigms. Problems are not solved as much as our engagement with the world is negotiated and tested iteratively. Given the complexity of climate change and its associated problems, design disciplines are particularly well suited to cultivate and push adaptation efforts. Design is the integrative lens through which tools like data modeling, scientific research and advanced engineering must be applied. Designers are the integral bridge essential to the implementation of solutions to problems at the interface of environment and society. Herbert Simon once said, "To design is to devise courses of action aimed at changing existing situations into preferred ones." (Simon 1969). At its core, design is aspirational in terms of our desire for something better than what we have. As climate change imposes an increasingly uncertain world we are going to have less predictability, less security about what comes next. We will not be able to "know" exactly what the future holds; instead we will have to explore, design, and envision future scenarios.

\section{DEFINING TRANSDISCIPLINARY RESEARCH}

Trans-disciplinary research has emerged as a methodology that extends research beyond the primacy of science and the primacy of practice, transforming the fundamental knowledge and methodologies that structure disciplines. "Trans-disciplinarity," according to Lang's definition, is a "reflexive, integrative, method driven scientific principle aiming at the solution or transition of societal problems and concurrently of related scientific problems by differentiating and integrating knowledge from various scientific and societal bodies of knowledge." (Lang 2009). Trans-disciplinary research is not purely theoretical or purely applied; it relies on the communication between theory and application. According to Stock, the method produces "Flexible methodologies driven by the context and problem." (Stock 2011) The method doesn't simply benefit from an ongoing dialogue between research and practice, but the ongoing feedback between the two is essential to the process. (Nassauer 2008)

Design thinking has become a common term referring to an applied problem-solving approach. Through this approach, problem-solvers go through a process based on the following five steps: empathize, define, ideate, prototype, test. (Brown 2009) This formal method for finding practical, creative solutions to intractable problems is fundamentally different from other research methods. Where the scientific method starts with a thorough definition of problem parameters, design thinking seeks to engage with the problem in an exploratory way, developing empathy (not distance) with actors through an iterative process of design. The definition of the problem, exploration or constraints, and determination of what means success are part of a fluid dialogue explored through design, iteration, and prototyping.

\section{AN OPENING FOR DESIGN INSTITUTES IN THE UNIVERSITY STRUCTURE}

Universities are becoming increasingly fragmented, spreading dwindling resources further over more discipline-specific and scientifically deep initiatives. The breadth of this pursuit without integration across disciplines leads to a flat research landscape punctuated by silos of intense specialization. As departments become increasingly disconnected behind narrow language, process, and culture; research centers can provide a means for researchers to connect to broader pursuits. Centers can focus curricula around pertinent societal issues while academic departments might be struggling with issues of accreditation or challenges associated with highly specialized research. The depth that the department brings to teaching and research is leveraged by the synthesis, integration, and real world application of the center, offering ways for academic institutions to respond to surrounding communities, transcend academic isolation, and break down traditional barriers between departments and the outside world. By reaching beyond university to other groups, centers are one of few ways universities regularly reach out to the public. (Larson 2000)

Some colleges of design in particular are facing funding shortages, student enrollment declines, and overall questions of direction in a rapidly changing design and planning profession. Adding measurably to this, schools of architecture are increasingly burdened with accreditation requirements often focusing curricula deeper into discipline specific skillsets. The emergence of research centers that connect design to fields outside the normal bounds of architectural production provides opportunities for faculty and students to contribute highly specialized skills to often intractable socio-ecological problems.

In terms of funding, centers operate fundamentally differently from the traditional architecture department, often relying heavily, if not exclusively, on external sources. This represents a significant change in design schools that are often tuition driven. External grants and donations, foundations, state or federal agencies, or the sale of products or services are primary funding resources available to centers. Thus, success of a center is largely reliant on links and relationships developed to publicize, make work visible, and continue to develop 


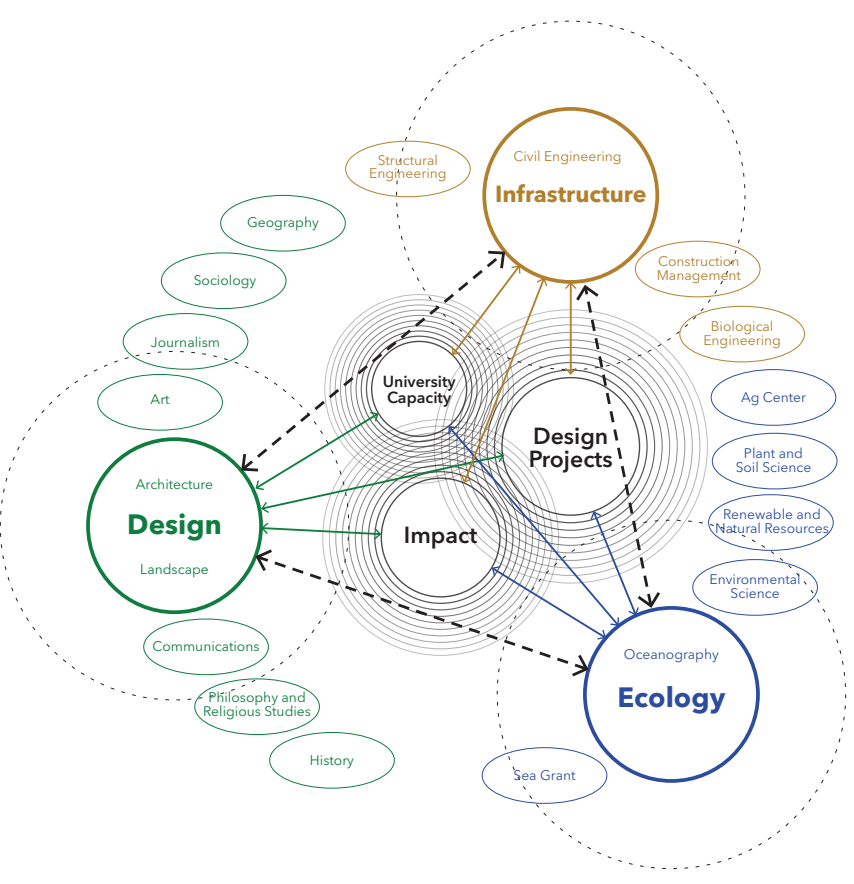

Figure 1: LSU Coastal Sustainability Studio diagram showing the range of research partners involved across campus.

community impact. (Roberts 2004) The benefits to the department, faculty, and students that the center can provide are relevant questions, projects, clients, and funding for research. In addition, this type of center can link and apply primary research from other parts of the university using the particularly useful skills and process of design, leveraging the resource of the studio environment to the center's success.

Centers have great potential to augment architectural education and research. As a practice-based field, it is our responsibility to engage in the specific challenges we face in society and integrate this into our teaching. The center should model practice in many ways. Studio-based education is the bridge that our process develops between research, education, and practice. It is a model of practice without competing or losing the independence of the educational process. Expanding this model beyond the college of design can provide a source of leadership among increasingly fragmented departments (Duderstadt 2004).

There are clear opportunities for design but also major challenges that this type of research operation can bring to design education and research. The opportunity for funding, political agency, and increased professional breadth drives many designers towards this opportunity; however, it is important not to underestimate the threat (real and perceived) that can undermine the credibility of the center and lead to conflict within a faculty. There is a potential that projects brought through the center become compromised when "real-world" problems are not only theoretically investigated but also funded locally, supported by policy makers or others with a real stake in the outcome, or lead to recommendations that are not supported by elements of a community. It is essential that a center clearly articulate contractually a clear path for creative investigation and expression. Design education prepares students for practice but it is important to maintain a well-defined space between research, academia, and actual practice. The completely unencumbered design experience that often separates academic design from the practice can become mixed in the research center.

\section{CASE STUDY: THE LSU COASTAL SUSTAINABILITY STUDIO}

The Coastal Sustainability Studio (CSS) emerged in 2009 in response to the tremendous challenges Louisiana faced after Hurricane's Katrina, Rita, Gustav, and Ike. Across research, governance, and private industry, Louisiana took on the challenges posed by these storms through aggressive planning, design, and environmental restoration. In response to these challenges ranging from community resilience and adaptation, large-scale environmental restoration, and storm protection, trans-disciplinary efforts have emerged to move intractable problems towards effective design process and solutions. The CSS has built a network of disciplines behind a methodology of design thinking, ecosystem design, and performance modeling. For six years the CSS has been revitalizing stagnant curriculum, building professional influence in coastal planning and design, producing visualization tools to communicate complex science, and challenging state officials to design boldly for future challenges and opportunities.

The challenge of sustaining the ecological, settlement, and economic framework of the gulf region is one of the most pressing issues for coastal Louisiana and coastal regional globally. Our goal is not only to reduce measurable risk to communities but to raise the capacity of the built environment to incrementally adapt in an increasingly dynamic context where land and water meet. A principle method of our work is the advancement of trans-disciplinary partnerships between scientists, engineers, architects, landscape architects, and planners linked together through the process of design.

Through state funded contracts, grants, and competitions the CSS has achieved a significant position in shaping the coastal landscape through design leadership. This research center has developed a design-based approach that brings together designers, planners, scientists, and engineers to intensively study and respond to the interdependent issues surrounding human settlement, coastal restoration, and flood protection. The center focuses its work around four primary themes:

- Education and capacity building

- Visual communication

- Community resilience, advocacy, and planning

- Design speculation

Each is described below through a description of the theme then articulated further through a brief description of a CSS project. ${ }^{1}$

\section{EDUCATION AND CAPACITY BUILDING: IMPLEMENTATION OF THE “DELTA RESEARCH MINOR" HOUSED IN THE COLLEGE OF ART + DESIGN}

Integrated systems-thinking approaches are needed to meaningfully address the most pressing issues facing the Gulf Coast and create sustainable ecological, economic, and human settlement frameworks. 


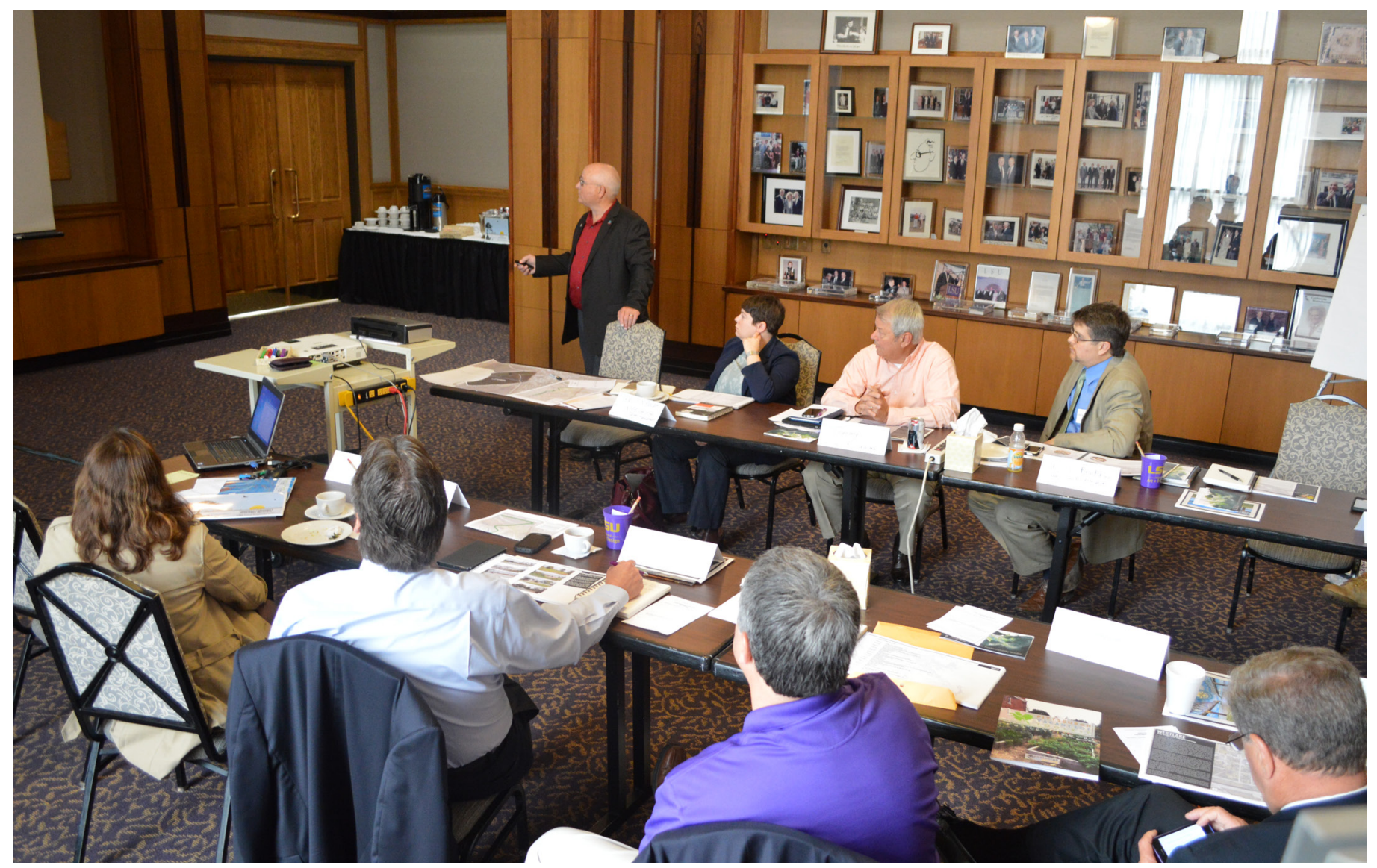

Figure 2: Mayors and resource team members working together on community resilience issues at the Louisiana Community Resilience Institute.

This requires transdisciplinary collaboration. Capacity building among these groups is crucial in order to connect experts, create interdisciplinary teams, and build a collective body of knowledge and understanding that crosses disciplinary boundaries. The CSS achieves this by funding interdisciplinary research, creating opportunities for cross-disciplinary networking and knowledge-sharing, and training students through internships and program curricula at LSU.

The CSS has built a collaborative effort with the LSU College of the Coast \& Environment, College of Engineering, and College of Art + Design to create a new multidisciplinary undergraduate applied research minor. The program, located in the College of Art + Design, is slated to be officially open to students in Spring 2017, however courses began Spring 2016. Built around a collaborative, "design thinking" methodology, curricular components of the Delta Research Minor (DRM) are systems ecology and ecosystem design, fieldwork methods in the Louisiana landscape, and an integrated design thinking studio course. Coursework will be augmented with a professional internship, a faculty-mentored final research project, and a final seminar that culminates in a public exhibition of thesis and final projects from a broad range of majors.

The goal of the DRM is to introduce design and research methods from a range of fields to enable students to research and solve problems across the arc of their undergraduate careers. This will prepare them for a rapidly changing design and research practice upon graduation. The program provides them training in applied research, effective communication, and problem solving for the emergent challenges facing coastal Louisiana and similarly vulnerable coasts worldwide.

Visual Communication: Design of the permanent exhibition called "Shifting Foundations" in the state-funded Center for River Studies

Visualizations provide a powerful platform for communicating complex ideas. Understanding the challenges facing coastal Louisiana requires an understanding of the history and context of place, the structure and function of natural systems, the engineering of economic, industrial, and social systems, and the perspectives that derive from and shape individual experiences and beliefs. Developing processes and solutions to solve problems of this level of complexity requires us to see and communicate across disciplines. Through a trans-disciplinary and iterative process, the CSS creates and employs visuals to stimulate thoughtful explorations, encourage dialogue, and ultimately galvanize action.

Through a contract with the Coastal Protection and Restoration Authority (CPRA), CSS is building the CPRA Visualization and Communication Program, tasked with developing materials to support the internal communication, design and development, and public education and engagement goals of the CPRA. The CPRA 


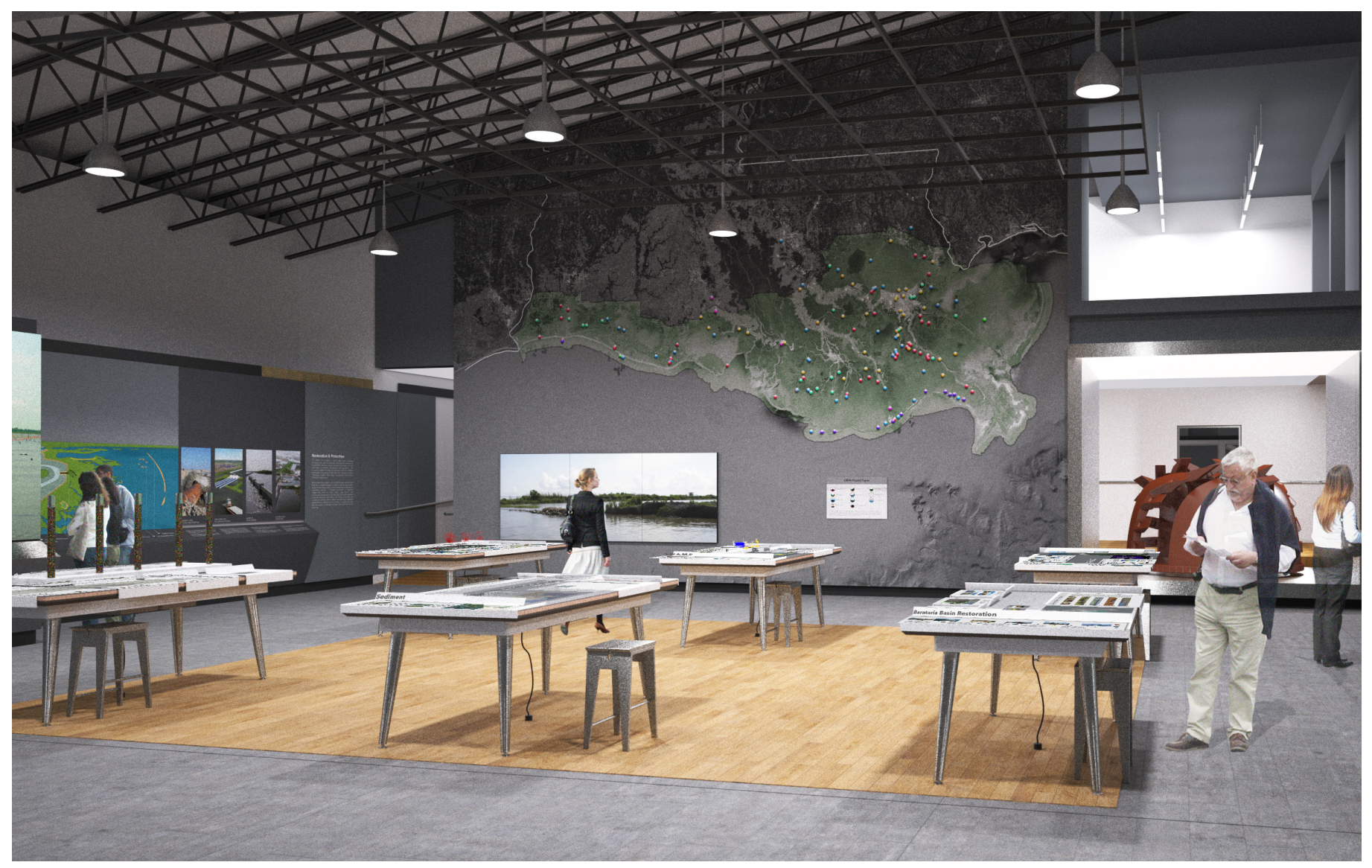

Figure 3: Conceptual Rendering of the main exhibit hall of the Center for River Studies exhibition: Shifting Foundations designed by the CSS.

is strategically working to restore and sustain coastal Louisiana, improve flood water management, and enhance protective infrastructure across the state. The state is investing roughly $\$ 1$ billion per year over the next 50 years on projects through the Coastal Masterplan for a Sustainable Coast.

This program goes far beyond science communication to apply design thinking to the process of conceiving of, and communicating the principles of coastal restoration to citizens and policy makers. By visually communicating the scientific data, project designs, advanced research, and future plans of CPRA, these tools increase awareness and understanding of highly technical information, thereby enriching public engagement and allowing citizens to make informed decisions.

As part of this effort, the CSS is currently completing design of the Center for River Studies on the Water Campus in downtown Baton Rouge. The 9,000 square foot exhibition space and development of exhibit content is to be located in the Center for River Studies which houses a physical model built to test hydraulic and sediment dynamics along the lower Mississippi River. The design of this space reinforces the trans-disciplinary nature of coastal design and research: to foster an ongoing dialogue between scientific researchers and designers in the development of ongoing and effective solutions to coastal problems.
COMMUNITY RESILIENCE, ADVOCACY, AND PLANNING: SYNTHESIS AND ENGAGEMENT THROUGH THE LOUISIANA RESILIENCY ASSISTANCE PROGRAM (LRAP) AND LOUISIANA COMMUNITY RESILIENCE INSTITUTE (LCRI)

CSS projects deal specifically with issues pertinent to coastal Louisiana and are developed through collaboration with local partners. Our work aims to reduce economic losses and protect assets, promote a sustainable coastal ecosystem through utilizing natural processes, provide suitable habitats to support an array of commercial and recreational activities, promote resilient coastal community design and development, and contribute to sustaining the unique heritage of coastal Louisiana.

Resilience design and planning augment traditional land use planning with information and expertise from various fields, particularly disaster science, floodplain management, climate, and environmental sciences. The process and outcomes of this emerging field of research and practice is to build community and state level capacity to respond and adapt to disturbances. LRAP was founded and developed by the CSS with the State's Office of Community Development - Disaster Recovery Unit (OCD-DRU) and with funding from the U.S. Department of Housing and Urban Development (HUD). The mission of LRAP is to collect, develop, house, and disseminate current planning efforts, resources, and best practices to promote, assist, and build networks around resiliency planning in Louisiana. The Louisiana Community 


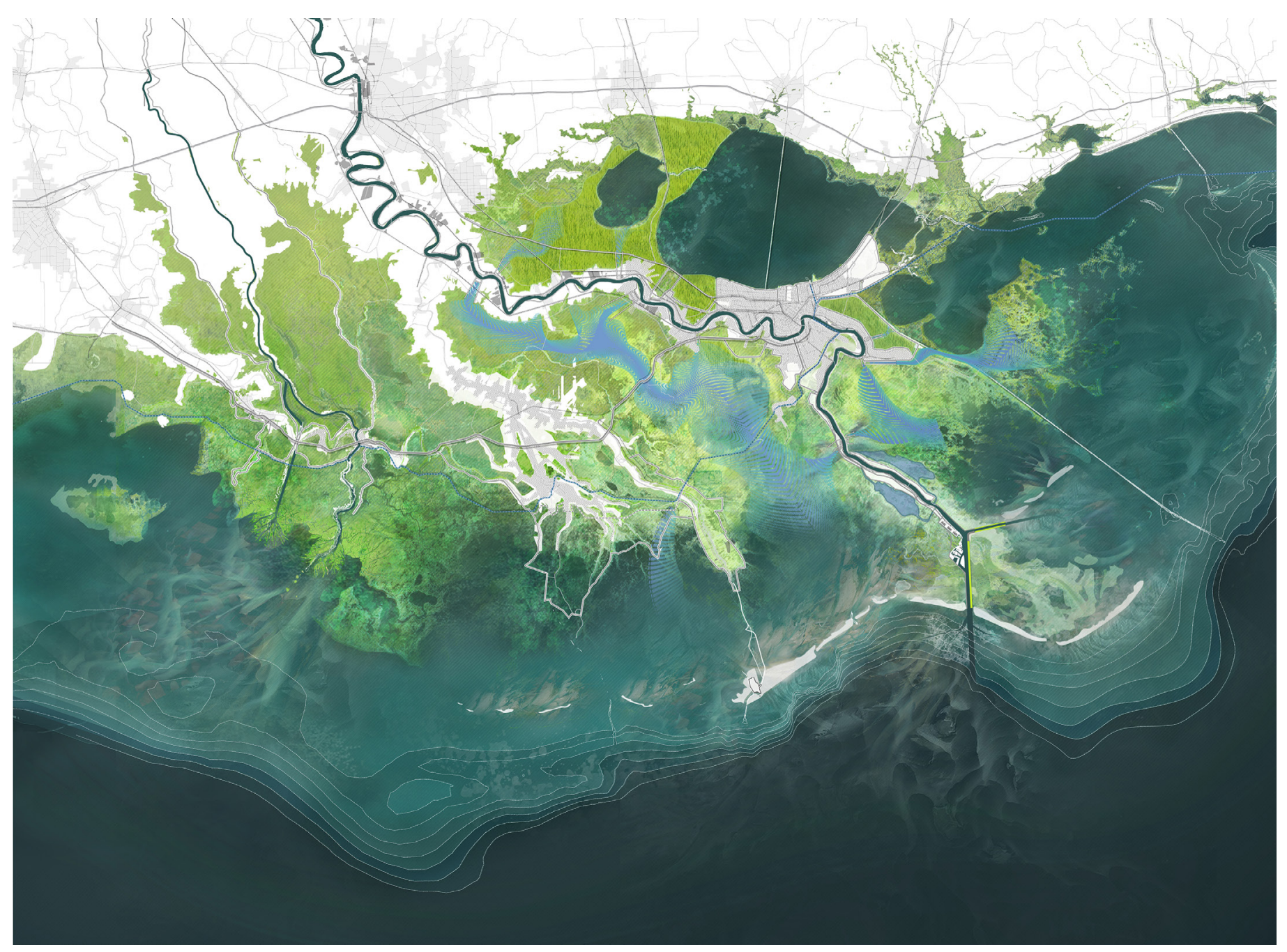

Figure 4: 100 year plan for the Mississippi River Delta Developed for the Changing Course Competition (Moffat \& Nichol, West 8, LSU CSS)

Resilience Institute (LCRI) was created as an extension of the LRAP. Since 2012, LRAP has hosted numerous webinars, statewide workshops, and two Mayors' Institutes. LRAP's core strength is to serve as a platform for assembling a broad range of academics and practitioners to increase resilience through efforts in coastal communities. Academic research and practical applications are simultaneously tested, enabling research and practice to learn from each other and advance the application and theory of community resilience.

\section{DESIGN SPECULATION: "THE GIVING DELTA", A WINNING PROJ- ECT IN THE “CHANGING COURSE” DESIGN COMPETITION.}

CSS regularly engages in design speculation as a means to research and explore the complex challenges posed by occupying a deltaic landscape, and allows for the space to imagine potential futures. Through design speculation, CSS puts forward new ideas and reimagines future possibilities for coastal Louisiana (and other modern deltaic systems worldwide). These designs are provocative and make proposals that challenge our assumptions, expand our understanding of the subject matter, and facilitate the creation of bold, innovative solutions.
Because of the engagement of so many disciplines, these projects have gone far beyond provocative design speculative to inform real policy and decision-making.

The design competition "Changing Course" selected three multidisciplinary design teams in a search for a bold, yet implementable, framework for the next century on the Mississippi River below New Orleans. The aim was to maintain the navigation corridor that the Lower Mississippi provides to the nation while simultaneously providing for human settlement and sustained ecosystem function. The CSS was on a team co-led by CSS, Moffat \& Nichol (engineering), and West 8 (landscape architecture). Our team also included the RAND Corporation, Deltares, and the University of New Orleans.

Our team proposed a retooling of the management of the Mississippi River as the primary driver of restoration, protection, development, and economic decisions. This radical departure from the highly engineered 20th century river effects all aspects of settlement along the river and the greater delta.

We were a part of a large team that brought nine investigators to a team of roughly 35 participants located around the world. The CSS portion of the team represented 7 distinctly different disciplines. The success of our team and the value of this to the university was that 
the institute structure enabled us to bring tremendous research depth

to a problem that essentially operated in a design practice format. The design approach was novel and a bit uncomfortable for the science community, but in the end proved to be an effective method for getting a tremendous range of ideas on the table in rather short time.

\section{CONCLUSION}

In conclusion, the integration of design thinking and trans-disciplinary research using an institute model can bring designers and colleges of design tremendous agency and significant funding opportunities for integrated and applied research. This can empower architecture schools to not only participate in, but lead climate change adaptation efforts. This could present a transformative opportunity for the field.

The four CSS projects discussed capture larger themes that bolster a broad application of design thinking to practice and research within and beyond the discipline. These projects have brought significant funding into the center; built institutional capacity through staff, equipment, and space; benefitted students through research assistantships and applied coursework; supported faculty through funded research, trans-disciplinary partnerships, and ample publication opportunities. Over the span of six years the CSS has been able to shape the educational and research landscapes of the university and affect real change in the communities that make up our state and region.

\section{BIBLIOGRAPHY}

Brown, T., \& Kātz, B. (2009). Change by design: How design thinking transforms organizations and inspires innovation. New York: Harper Business.

Davoudi, S. (2012). Resilience: A Bridging Concept or a Dead End?. Planning Theory \& Practice, 13(2), 299-333. doi:10.1080/14649357.20 12.677124

Duderstadt, J. (2004). Fixing the Fragmented University: A View from the Bridge. Working Paper. University of Michigan

Lang, D. J., Wiek, A., Bergmann, M., Stauffacher, M., Martens, P., Moll, P., .. . Thomas, C. J. (2012). Transdisciplinary research in sustainability science: Practice, principles, and challenges. Sustainability Science Sustain Sci, 7(S1), 25-43. doi:10.1007/s11625-011-0149-x

Larson, S., Long, R. (2000) Academic Centers: Moving Beyond the Periphery. Journal of Public Service and Outreach. Volume 5, Number 2.

Nassauer, J. I., \& Opdam, P. (2008). Design in science: Extending the landscape ecology paradigm. Landscape Ecology Landscape Ecol, 23(6), 633-644. doi:10.1007/s10980-008-9226-7

Roberts, J. (2004). Riding the Momentum: Interdisciplinary Research

Stock, P., \& Burton, R. J. (2011). Defining Terms for Integrated (MultiInter-Trans-Disciplinary) Sustainability Research. Sustainability, 3(12), 1090-1113. doi:10.3390/su3081090

\section{NOTES}

1 Theme and project descriptions have been excerpted from a recent collection of CSS work "The Coastal Sustainability Studio - A Collection of Works: 2009-2015". The document can be downloaded in full here: http://css.Isu.edu/publications/ downloadable-publications/ 